\title{
Knowledge, Attitude, Perceptions and Practices of Physical Training Instructors of School Athletes Regarding Orofacial Injuries and Mouth Guard Use by the Athletes
}

\author{
Aysha Shibin A.R. ${ }^{1}$, H.T. Ajay Rao ${ }^{2}$, Sham S. Bhat ${ }^{3}$, Sundeep Hegde K ${ }^{4}$, Shailesh Shenoy ${ }^{5}$, \\ Nanditha Hegde ${ }^{6}$, Reshma Suvarna ${ }^{7}$, Sharan S. Sargod ${ }^{8}$ \\ 1, 2, 3, 4, 5, 6, 7, 8 Department of Pedodontics and Preventive Dentistry, Yenepoya Dental College, \\ Yenepoya University, Deralakatte, Mangalore, India.
}

\section{ABSTRACT}

\section{BACKGROUND}

Dental trauma is one of the most common presentations of children to a paediatric dentist and can be distressing for both the child and the parent. Incidence of such injuries can be reduced with the usage of oral protective devices. Many studies have demonstrated that wearing a mouth-guard can significantly reduce the incidence of orofacial injuries. Usage of mouth guards by the sports person largely depends on the awareness of their coaches. Hence this study aims to evaluate the knowledge and attitude of the sports instructors of school children regarding orofacial trauma and mouth guard usage. We wanted to evaluate awareness and knowledge of school physical trainers about orofacial injury relating to sports and assess their awareness regarding mouth protectors.

\section{METHODS}

This is an observational cross section study. A multiple-choice questionnaire was prepared consisting of questions regarding knowledge on sports injuries and mouth guards. 250 physical education teachers from schools in and around Mangalore participated in the study. Study period was 2 years. Descriptive statistics was used for the data analysis.

\section{RESULTS}

$52 \%$ of the physical training instructors of schools in Mangalore reported that the sports activities supervised by them caused orofacial injuries and the most common reason was fall during the sport. $72.8 \%$ of physical education instructors believed that mouth guards must be used by school athletes. $82.4 \%$ of the participants showed interest in having more information about orofacial injuries and effectiveness of mouth guards.

\section{CONCLUSION}

Majority of physical instructors of schools in Mangalore agreed on the protective effectiveness of mouth guard against sports related orofacial injuries. There is a need to popularize the use of orofacial protective devices in a variety of sports activities in our country by interaction with sports persons and coaches of schools and sports academies. Also it is the responsibility of dentists and other healthcare professionals to familiarize themselves and educate the athletes and their coaches regarding prevention of sports injuries.

\section{KEY WORDS}

Sports Injury, Mouth Guard, Awareness
Corresponding Author:

Dr. H.T. Ajay Rao,

Professor, Department of Pedodontics and Preventive Dentistry,

Yenepoya Dental College,

Yenepoya University,

Deralakatte, Mangalore, India.

E-mail: drajayrao@gmail.com

DOI: $10.14260 / j e m d s / 2020 / 823$

How to Cite This Article:

Shibin AAR, Rao HTA, Bhat SS, et al. Knowledge, attitude, perceptions and practices of physical training instructors of school athletes regarding orofacial injuries and mouth guard use by the athletes. J Evolution Med Dent Sci 2020;9(49):37483752, DOI: $10.14260 /$ jemds/2020/823

Submission 26-08-2020,

Peer Review 20-10-2020,

Acceptance 26-10-2020,

Published 07-12-2020.

Copyright (c) 2020 Aysha Shibin A.R. et al. This is an open access article distributed under Creative Commons Attribution License [Attribution 4.0 International (CC BY 4.0)] 


\section{BACKGROUND}

Children of today are very enthusiastic in the field of sports. One consequence of this active involvement of children in play and sports is a higher proportion of sports related injuries. Dental injuries are the most common type of orofacial injuries sustained during sports activities. ${ }^{1} 19.2 \%$ to $36 \%$ of all athletic trauma involves dental injuries and are most commonly seen in the age group of 8 to 11 years..$^{2,3}$

The incidence of oral trauma, concussions, cerebral haemorrhage, loss of consciousness and also death due to a number of mechanisms during the athletic involvement can be reduced just by the usage of orofacial protective devices. However, minimal utilization of mouth guards has been reported in athletes, in spite of the availability and awareness. 4,5

A mouthguard (UK: gumshield) is a protective device for the mouth that covers the teeth and gums to prevent and reduce injury to the teeth, arches, lips and gums. Johnsen and Winters ${ }^{6}$ report that by protecting against injuries, mouth guards may have disadvantages like discomfort, tissue reaction. Mouth guards can also impair normal breathing and normal speech, or restrict the intake of fluids.

There are three types of mouth guards; the ready-made, or stock, mouth guard; the mouth formed "boil-and-bite" mouth guard; the custom-made mouth guard made by a dentist.

All properly fitted mouth guards provide varying degrees of protection. A custom-fitted mouth guard professionally made in the dental office can be tailored to the demands of the athlete and the sport. The most effective mouth guard should have several features. It should be resilient, tear-resistant and comfortable. It also should fit properly, be durable and easy to clean, and not restrict your speech or breathing.

Attitude and knowledge of coaches, officials, parents and players regarding mouth guards largely influences its usage. Although there are many evidences and studies regarding this piece of athletic equipment in the prevention of oral trauma, the usage has not been made mandatory yet universally. Sports coaches have maximum impact on whether or not players wear mouth guards. ${ }^{7}$

Since sports have been implicated in the aetiology of dental trauma, and a majority of dental trauma occur at school during games or sports classes, it would be desirable for coaches and physical education teachers to be capable of managing such injuries when they occur. For this the physical instructors at school need to be aware of orofacial injuries that can be encountered during sports and also know about the protective devices that can be used by their athletes to avoid such incidences.

Hence, the study was taken up to assess the knowledge, attitude, perceptions and practices of physical training instructors of school athletes in and around Mangalore, regarding orofacial injuries and mouth guard use by the athletes.

\section{METHODS}

This is an observational cross section study conducted over a period of two years. A total of 250 physical education teachers of schools in and around Mangalore participated in this survey based on the availability. All the available subjects who were willing to participate in the survey were included in the study. Before scheduling the present study, the required ethical clearance was obtained. Approval from the block education officer was also obtained to conduct the study. Permission for conducting the survey in the schools was obtained from the principal / headmaster / head mistress of the respective schools. The questionnaire was formulated based on similar studies and validated by the concerned authorities from the college university. Before the data collection, the purpose and the methodology of the survey was explained to each of the physical education instructor and informed consent was obtained. Data was collected through a survey, which included a self-administered questionnaire.

\section{Statistical Analysis}

Descriptive statistics was used for the data analysis.

\section{RESULTS}

The results of the survey showed $52 \%$ of the physical training instructors of Mangalore schools reported the sports activities supervised by them causing orofacial injuries and the most common reason given of such dental trauma was fall during sport activity. (Figure 1). Sports related injuries were managed with first aid by $38.4 \%$ of the coaches. $37.6 \%$ consulted a dentist and $20 \%$ took advice of physicians. $58.4 \%$ of the coaches have discussed about the safety measures in sports, majority of which was during their physical education degree course, while few others heard about it during sports career programs or seminars. The rate of concern expressed by parents of sports persons regarding sports related injuries is as high as $84.8 \%$. Most of the coaches also noticed that girls were more concerned about such injuries. Sports related orofacial injuries observed by the coaches in the last year was in the range of $1-5$ incidence by $28 \%$ of the coaches and a significant relation to it was the non-use of protective devices. (Figure 2). As high as $77.2 \%$ of coaches agreed that such injuries sometimes caused their students to discontinue the sport, which prompted them to advise the usage of a protective gear. Also $62 \%$ of the coaches feel that the use of protective devices will enhance the efficiency of the athlete. (Figure 3)

$87.2 \%$ of coaches claim to have been aware about the prevention of dental injury by mouth guard. (Figure 4). $72.8 \%$ of physical education instructors do believe that mouthguards must be used by school athletes although the usage seen by their students was very minimal. Mouthguards prevent orofacial injuries according to $73.2 \%$ of the physical education teachers. Sports injuries and prevention was a part of physical education syllabus during their professional degree according to $80 \%$ of the trainers who participated in this survey. According to the instructors, sports person's reason for not using the mouthguard were mainly speech difficulty (33.6\%) and unavailability (28.8 \%) (Figure 5). $52.4 \%$ of the coaches feel that the usage of mouth guards can influence an athlete's performance. $82.4 \%$ of the physical education teachers of schools showed interest in having more information about orofacial injuries and effectiveness of mouth guards. 

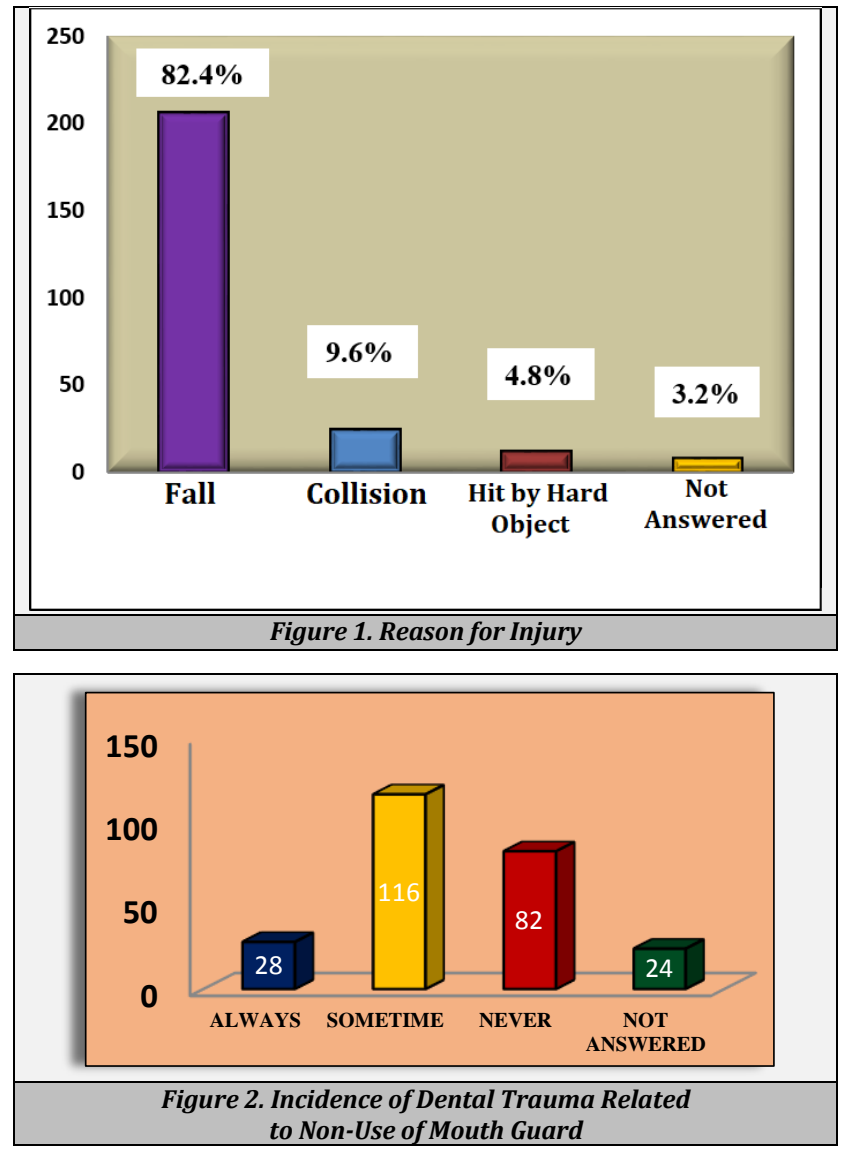
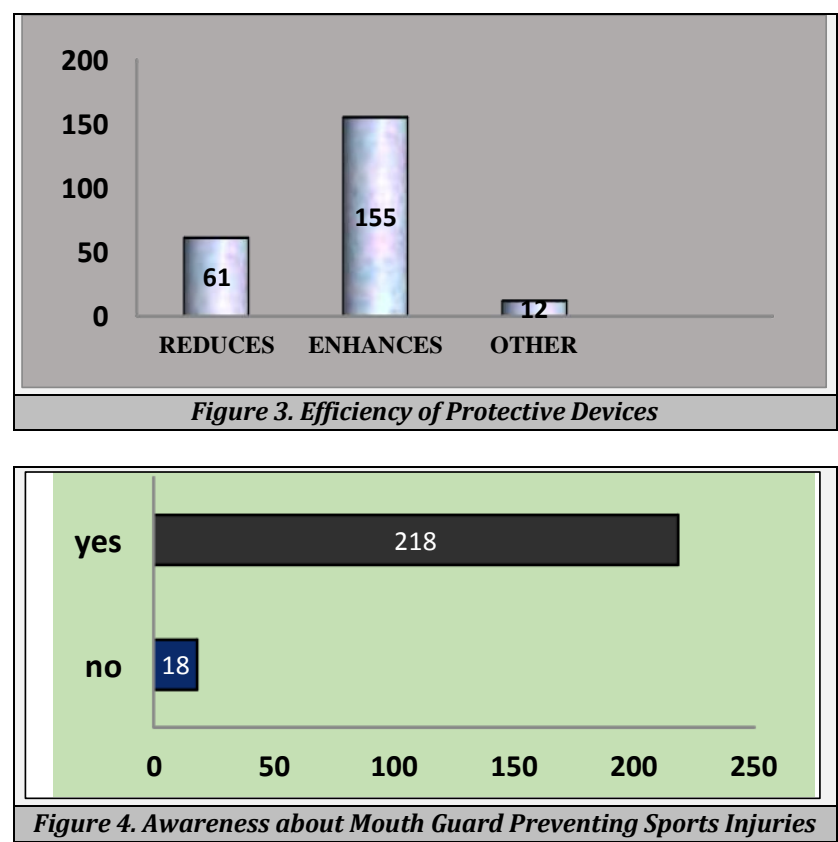

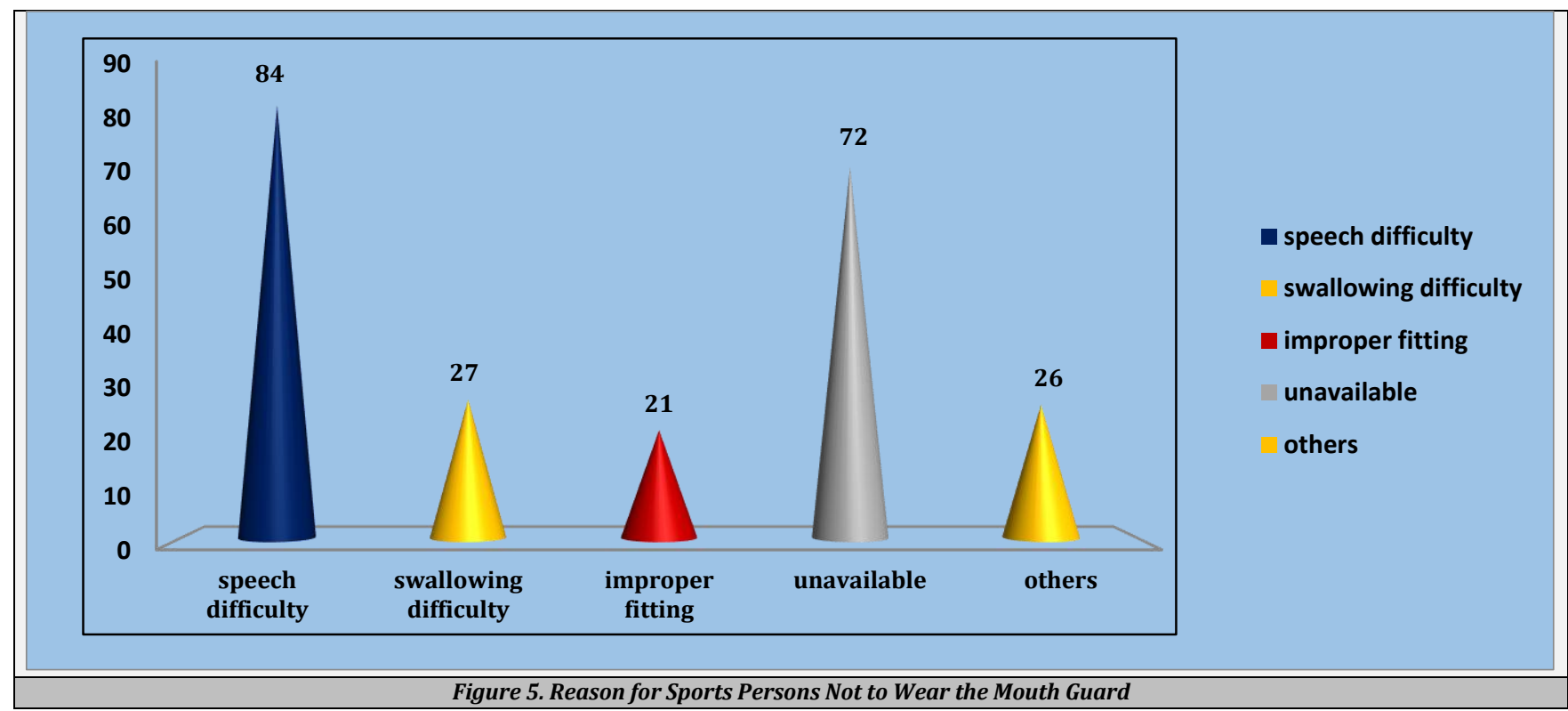

\section{DISCUSSION}

Dental trauma is considered as a major public oral health problem because of the high prevalence and impact caused in daily life. ${ }^{8}$ It has been shown that sports practice increases the risk of traumatic injuries such as dental trauma. ${ }^{9}$ As long as young children remain active, trauma to both primary and permanent dentition continues to be a frequent dental problem. It is known that majority of dental injuries is seen in children between ages of 8 and 11 years. ${ }^{10-12}$ According to Welbury RR (1996), although less marked, adolescence is another peak time of sports related injuries besides the main 'peak periods' for dental injury, which is described as being between the ages of $1-3$ years and $7-10$ years. ${ }^{13}$

Mouth guards are resilient appliances that reduces orofacial injuries when placed in the mouth, particularly to the teeth and surrounding structures. This oral equipment helps to distribute the impact of a "blow" evenly, lessening the chances of injury. They are most commonly made from Ethylene Vinyl Acetate (EVA). As it is non-toxic, elastic, has minimal moisture absorption, and also because of the ease of manufacture, the use of mouth guard is highly recommended. ${ }^{14}$ Since sports have been implicated in the 
aetiology of dental trauma ${ }^{15}$ and a high proportion of dental trauma at school occurs during classes in physical education, ${ }^{16}$ the present study focuses on the physical education teacher's knowledge and perceptions about sports related orofacial injuries and also evaluates the awareness and attitude regarding mouthguards.

In the present study, 250 physical education teachers of various schools in Mangalore readily participated in the survey where they had to complete a self-administered questionnaire which comprised of questions regarding orofacial injuries during sports activities of school children and mouthguards that evaluated their knowledge and awareness regarding the same.

$52 \%$ of coaches who participated in the study agreed that the sport supervised by them causes orofacial injuries and up to $82.4 \%$ of the injuries were caused mainly due to fall during the sport activity, followed by collision and hit by hard object. Sports most likely to cause trauma according to majority of them was kabbadi, kho-kho, boxing, basketball and football which are the more commonly played sports in the schools of Mangalore. Studies done by Kvittem et al (1998) ${ }^{17}$, Blinkhorn et al (2000) ${ }^{18}$ and Ferrari et al $(2002)^{19}$ suggested that injuries are most prominent in soccer, basketball, hockey and boxing.

The physical education teachers in the present study reported that $38.4 \%(n=96)$ of the injuries were managed with first aid, $37.6 \%$ of them consults a dentist and $20 \%$ goes to a physician for emergency care. The preference of taking the child to a dentist by the physical education teachers may be attributed to the increased availability of healthcare facilities ${ }^{21}$ in Mangalore. 146 instructors out of the 250 had interactions with medical or dental experts regarding safety measures concerning dental injury. $26 \%$ of the coaches had interactions during their physical education course. Few others reported to have the interaction casually and during seminars i.e., $15.2 \%$ and $12 \%$ respectively.

Majority of the instructors indicated that there was an increased concern by parents of sports persons regarding sports injury and that many had to opt out of the sport to avoid the trauma. The study suggested that girls were more concerned about such injuries. Onyeaso CO et al (2004) ${ }^{14}$ in his study revealed that boys significantly had more injuries than girls. The orofacial trauma rate in a study conducted by Cetinbas $\mathrm{T}$ et al $(2006)^{9}$ was $13.2 \%$ and all the injuries happened was while mouth guard were not being used. There were no injuries reported by athletes to have happened while using a mouth guard.

$28 \%$ physical trainers in the present study accepted that they have encountered with 1 - 5 incidences of such orofacial trauma in the last one year. More than 6 similar incidences per year were witnessed by $13.6 \%$ of the coaches. According to $32.8 \%$ of coaches, dental trauma was never due to non-use of mouth guards. However, few others did admit that the incidence of dental trauma occurred when the sports person was not wearing a mouth guard. Stenger et $\mathrm{al}^{21}$ reported in their study that in football, with introduction of face masks, dental injuries were reduced to almost half (50\%) and with the addition of mouth guards the number of dental injuries in this sport further decreased to $1.4 \%$.

Traumatic injuries during sports prompted the coaches to advise protective gears. A higher percentage of the physical instructors believed that using a protective device will avoid dental trauma and enhance the efficiency of the sports person although 61 of them thought it can reduce the efficiency.
Yamada et $\mathrm{a}^{22}$ reported that many soccer athletes had insufficient knowledge about mouth guards and were not concerned about preventing oral injury, although it was, in fact a common problem in their sport in Japan.

$72.8 \%$ of the coaches who participated in the study believes that school athletes must make use of mouth guards. McNutt et $\mathrm{al}^{23}$ reported that it was apparent that oral injury had been reduced in football due to mandatory enforcement of mouthguard use. Onyeaso and Adegbesan's study ${ }^{24}$ reported that $88.1 \%$ of coaches involved in their study group had rated their athlete's acceptance of mouth guards as favourable. Berg et al $^{7}$ indicated that advocacy for mouth guard use should focus on coaches, coaches' associations and rule-making organizations.

In the present study, $18 \%$ of the coaches reported usage of mouth guards by their students although very minimal in number. The usage was limited only to hockey players. Large number of respondents feels that mouth guards can prevent oral injuries and 209 of them claimed to have awareness regarding the same. Most of the participants were aware that mouth guards offer protection to teeth as well as jaws similar to the study conducted by Moreira $\mathrm{A}$ et $\mathrm{al}^{25}$ and they emphasized on the mandatory usage of protective device in sports like kabbadi, boxing, hockey and kho-kho.

Speech difficulty and unavailability of mouth guards were the common reasons reported by the respondents for the nonuse by their athletes. Wenli Ma et $\mathrm{al}^{26}$ in his study indicated that $26.7 \%$ athletes considered mouth guards to be uncomfortable and that it hinders communication. Similar results were obtained by Praveena et $\mathrm{al}^{27}$. Expense involved was the major concern as per the study conducted by Sethi et al. ${ }^{28}$

The physical education teachers of schools in Mangalore considered orofacial injuries during sports activity as a major threat and hence, as high as $82.4 \%$ of them wanted to have more information regarding the prevention of such injuries and the advantages of mouth guards which is a good appreciable attitude. Hence, there is a need to educate and motivate the school authorities and also government to come up with rules for the mandatory use of protective device during sports activities.

The present study has its own limitations as we have included only the physical education teachers of schools in Mangalore. Sports academy coaches were excluded. Also, that the participants were included irrespective of specialized game, age and sex.

The study suggests that dentists must be more involved in providing information to the coaches about prevention of orofacial injuries. Paediatric dentists play an important role in educating and motivating the athletes and their physical instructors about orofacial injury risk and suggest the use of mouth guard.

\section{CONCLUSIONS}

Knowledge and awareness among the physical trainers of schools in Mangalore regarding potential orofacial injuries during sports activity were inadequate. It was also found that the overall rate of mouth guard usage among school athletes was very minimal. However, the majority of the participants of 
the study believed that mouth guards are effective in preventing injuries. There is a paucity of information regarding orofacial injury related to sports and its prevention. There is still a need for education and motivation regarding the same.

Data sharing statement provided by the authors is available with the full text of this article at jemds.com.

Financial or other competing interests: None.

Disclosure forms provided by the authors are available with the full text of this article at jemds.com.

\section{REFERENCES}

[1] Scott J, Burke FJ, Watts DC. A review of dental injuries and the use of mouthguards in contact team sports. Br Dent J 1994;176(8):310-4.

[2] Bijur PE, Trumble A, Harel Y. Sports and recreation injuries in US children and adolescents. Arch Pediatr Adolesc Med 1995;149(9):1009-16.

[3] Marcenes W, Alessi ON, Traebert J. Causes and prevalence of traumatic injuries to the permanent incisors of school children aged 12 years in Jaragua do Sul, Brazil. Int Dent J 2000;50(2):87-92.

[4] Neeraja G, Bharadwaj S, Shah K, et al. Knowledge, attitude, and practices regarding orofacial injuries and orofacial protective devices among physical instructors in Bangalore. J Int Oral Health 2014;6(3):1-6.

[5] O'Malley M, Evans DS, Hewson A, et al. Mouthguard use and dental injury in sport: a questionnaire study of National school children in the west of Ireland. J Ir Dent Assoc 2012;58(4):205-11.

[6] Johnsen DC, Winters JE. Prevention of intraoral trauma in sports. Dent Clin North Am 1991;35(4):657-66.

[7] Berg R, Berkey DB, Tang JM, et al. Knowledge and attitudes of Arizona high school coaches regarding oral facial injuries and mouthguard use among athletes. J Am Dent Assoc 1998;129(10):1425-32.

[8] Traebert J, Peres MA, Blank V, et al. Prevalence of traumatic dental injury and associated factors among 12year-old school children in Florianopolis, Brazil. Dent Traumatol 2003;19(1):15-8.

[9] Cetinbaş T, Sönmez H. Mouthguard utilization rates during sport activities in Ankara, Turkey. Dent Traumatol 2006;22(3):127-32.

[10] Andreasen JO. Effects of extra-alveolar period and storage media upon periodontal and pulpal healing after replantation of mature permanent incisors in monkeys. Int J Oral Surg 1981;10(1):43-53.

[11] Welbury RR. The prevention of dental trauma. In: Murray JJ, ed. The prevention of oral disease. $3^{\text {rd }}$ edn. New York: Oxford University Press Inc 1996:147-52.
[12] Kerr IL. Mouth guards for the prevention of injuries in contact sports. Sports Med 1986;3(6):415-27.

[13] Sarkar S, Basu PK. Incidence of anterior tooth fracture in children. J Indian Dent Assoc 1981;53:371.

[14] Onyeaso CO. Secondary school athletes: a study of mouthguards. J Natl Med Assoc 2004;96(2):240-5.

[15] Rai SB, Munshi AK. Traumatic injuries to the anterior teeth among South Kanara school children--a prevalence study. J Indian Soc Pedod Prev Dent 1998;16(2):44-51.

[16] Gabris K, Tarjan I, Rozs N. Dental trauma in children presenting for treatment at Department of Dentistry for Children and Orthodontics, Budapest, 1985-1999. Dent Traumatol 2001;17(3):103-8.

[17] Kvittem B, Hardie NA, Roettger $M$, et al. Incidence of orofacial injuries in high school sports. J Public Health Dent 1998;58(4):288-93.

[18] Blinkhorn FA. The etiology of dento - alveolar injuries and factor influencing attendance for emergency care of adolescents in the north west of England. Endod Dent Traumatol 2000;16(4):162-5.

[19] Ferrari CH, de Mederios JMF. Dental trauma and level of information: mouthguard use in different contact sports. Dent Traumatol 2002;18(3):144-7.

[20] Mohandas U, Chandan GD. Knowledge, attitude and practice in emergency management of dental injury among physical education teachers: a survey in Bangalore urban schools. J Indian Soc Pedod Prev Dent 2009;27(4):242-8.

[21] Stenger JM, Lawson EA, Wright JM, et al. Mouthguards: protection against shock to head, neck and teeth. J Am Dent Assoc 1964;69:273-82.

[22] Yamada T, Sawaki Y, Tomida S, et al. Oral injury and mouthguard usage by athletes in Japan. Endod Dent Traumatol 1998;14(2):84-7.

[23] McNutt T, Shannnon SW, Wright JT, et al. Oral trauma in adolescent athletes: a study of mouth protectors. Pediatr Dent 1989;11(3):209-13.

[24] Onyeaso CO, Adegbesan OA. Knowledge and attitudes of coaches of secondary school athletes in Ibadan, Nigeria regarding oro - facial injuries and mouthguard use by the athletes. Dent Traumatol 2003;19(4):204-8.

[25] Moreira A, Fonte E, Clemente M, et al. Orofacial trauma prevalence and mouthguard awareness in basketball players. Journal of Orthopaedics and Trauma 2019;9:1-6.

[26] Ma W. Basketball players' experience of dental injury and awareness about mouthguard in China. Dent Traumatol 2008;24(4):430-4.

[27] Praveena J, Battur H, Fareed N, et al. Orofacial injuries and use of protective wear among field hockey players of Coorg District, Karnataka, India - A KAP Study. Indian J Dent Res 2018;29(6):852-7.

[28] Sethi HS, Kaur G, Mangat SS, et al. Attitude toward mouthguard utilization among North Indian school children. J Int Soc Prev Community Dent 2016;6(1):69-74. 